\title{
Responsabilidades por incumplimiento de la regulación sobre prevención de riesgos laborales
}

Responsibilities for breach of the regulation on occupational risk prevention

\author{
Dra. María Concepción RAYÓN BALLESTEROS \\ Universidad Complutense de Madrid
}

Resumen: En el presente artículo se analiza brevemente el régimen de responsabilidades que establece la Ley de Prevención de Riesgos Laborales tanto para el empresario como para el trabajador con especial referencia a la responsabilidad civil, penal y administrativa.

Palabras clave: accidente de trabajo, prevención de riesgos laborales, responsabilidad administrativa, responsabilidad civil, responsabilidad penal.

Abstract: This article gives an overview about liability regime established in Spain by the Law on the Prevention of Occupational Risks for the employer as well as for the worker, with special reference to civil, criminal and administrative liability.

Keywords: work accident, occupational risk prevention, administrative responsibility, civil liability, criminal responsibility.

\section{Sumario:}

\section{Presentación.}

II. Responsabilidades del empresario.

2.1. Responsabilidad administrativa.

2.2. Responsabilidad de Seguridad Social. Recargo de prestaciones económicas en caso de accidente de trabajo y enfermedad profesional.

2.3. Responsabilidad penal. 
2.4. Responsabilidad civil.

2.5. Compatibilidad de los diferentes tipos de responsabilidad.

III. Responsabilidades del trabajador.

IV. Conclusiones.

Recibido: septiembre de 2019.

Aceptado: noviembre de 2019. 


\section{PRESENTACIÓN}

La Exposición de Motivos de la Ley 31/1995, de 8 de noviembre, de prevención de Riesgos Laborales (en adelante LPRL), concreta el "cuerpo básico de garantías y responsabilidades preciso para establecer un adecuado nivel de protección de la salud de los trabajadores frente a los riesgos derivados de las condiciones de trabajo, y ello en el marco de una política coherente, coordinada y eficaz de prevención de los riesgos laborales".

En el presente artículo vamos a detallar las diferentes responsabilidades que pueden surgir por el incumplimiento de la citada normativa sobre prevención de riesgos laborales. En primer lugar sintetizaremos lo relativo a las responsabilidades del empresario diferenciando la responsabilidad administrativa, penal y civil y posteriormente la responsabilidad del trabajador ${ }^{1}$.

\section{RESPONSABILIDADES DEL EMPRESARIO}

El art. 14 de la LPRL consagra un completo sistema de responsabilidad del empresario para referirse a responsabilidades civiles, penales y administrativas. Se trata de un régimen de responsabilidad objetiva del empresario que tiene una serie de obligaciones, a fin de garantizar la seguridad y la salud en el trabajo y reconociendo al trabajador el derecho a una protección eficaz en esta materia.

Esa obligación del empresario no es de resultado, por lo que el empresario cumplirá con su obligación genérica cumpliendo todos los mandatos específicos que concreta la legislación y poniendo todos los medios necesarios para que no se produzcan daños, aunque éstos finalmente se produzcan.

${ }^{1}$ El artículo 40.2 de la Constitución Española encomienda a los poderes públicos, como uno de los principios rectores de la política social y económica, velar por la seguridad e higiene en el trabajo. En este sentido la regulación de materia de prevención de riesgos laborales establece que los trabajadores tienen derecho a una protección eficaz en materia de seguridad y salud en el trabajo y, los empresarios, un correlativo deber de protección de los trabajadores frente a los riesgos laborales (art. 14 de la Ley 31/1995, de 8 de noviembre, de Prevención de Riesgos Laborales (en adelante, "LPRL”). 
El art. 42.1 LPRL enumera los distintos tipos de responsabilidades en los que puede incurrir el empresario en esta materia de prevención de riesgos laborales:

El incumplimiento por los empresarios de sus obligaciones en materia de prevención de riesgos laborales dará lugar a responsabilidades administrativas, asi como, en su caso, a responsabilidades penales y a las civiles por los daños y perjuicios que puedan derivarse de dicho incumplimiento.

Se trata de un precepto de carácter muy escueto, pero de capital importancia, que requiere de una serie de normas de desarrollo más pormenorizadas que establecen las responsabilidades empresariales ${ }^{2}$ como tendremos ocasión de examinar seguidamente.

Además, el mismo art. 42 en su número 3 establece la compatibilidad entre los distintos tipos de responsabilidad, entendiendo que cada una de ellas tiene una finalidad distinta:

Las responsabilidades administrativas que se deriven del procedimiento sancionador serán compatibles con las indemnizaciones por los daños y perjuicios causados y de recargo de prestaciones económicas del sistema de la Seguridad Social que puedan ser fijadas por el órgano competente de conformidad con lo previsto en la normativa reguladora de dicho sistema.

Como hemos indicado la LPRL establece cuatro tipos de responsabilidades que pueden surgir del incumplimiento empresarial:

- Responsabilidad administrativa

- Responsabilidad penal

- Responsabilidad civil

- Responsabilidad por recargo de prestaciones

Cada una de ellas tiene una regulación diferente que veremos a continuación.

\footnotetext{
${ }^{2}$ Este precepto necesita de la aplicación añadida de otros preceptos más específicos.
} 


\subsection{Responsabilidad administrativa}

La responsabilidad administrativa tiene carácter público, por tanto no se puede asegurar, y tiene carácter objetivo de manera que valora exclusivamente el incumplimiento de la normativa concurra o no actuación culposa o negligente del infractor y se haya producido o no un daño.

En este sentido nos referiremos a las responsabilidades que dan origen al procedimiento administrativo sancionador recogido en el Real Decreto Legislativo $5 / 2000$, de 4 de agosto, por el que se aprueba el texto refundido de la Ley sobre Infracciones y Sanciones en el Orden Social (en adelante LISOS) concretamente en la Sección II del Capítulo II "Infracciones en materia de prevención de riesgos laborales" establecidas en los art. 11 y siguientes. Persiguen la defensa del interés general a la salud en el trabajo y conllevan, como sanción típica, la multa. Para ello, en nuestro ordenamiento de prevención de riesgos laborales se encuentran previstas las infracciones y sanciones administrativas correspondientes que hacen posible que se impongan multas de cuantía importante para las empresas que incumplan las normas.

En estos casos no es necesario que exista un accidente de trabajo, sino que es sancionable el hecho de incumplir las normas.

La administración competente, en el ámbito nacional o autonómico, seguirá el procedimiento sancionador legalmente establecido al efecto. Las infracciones en materia de prevención de riesgos laborales podrán ser de tres tipos:

- Leves ${ }^{3}$ con imposición de multas desde los $40 €$ hasta los $2.045 €$;

- Graves ${ }^{4}$ con imposición de multas desde los $2.046 €$ hasta los $40.985 €$;

- Muy graves ${ }^{5}$, con multas desde los $40.986 €$ hasta los $819.780 €$, de conformidad con la clasificación establecida por la mencionada normativa.

Además de las multas también pueden imponerse al empresario otro tipo de sanciones como las siguientes:

${ }^{3}$ Art. 11 Real Decreto Legislativo 5/2000, de 4 de agosto, por el que se aprueba el texto refundido de la Ley sobre Infracciones y Sanciones en el Orden Social.

${ }^{4}$ Art. 12 Ley sobre Infracciones y Sanciones en el Orden Social.

${ }^{5}$ Art. 13 Ley sobre Infracciones y Sanciones en el Orden Social. Además, las sanciones impuestas por infracciones graves o muy graves se harán públicas y constarán en un registro en cada una de las administraciones competentes, de acuerdo con los arts. 49.5 LPRL y 40.2 LISOS. 
- La suspensión de las actividades laborales por un tiempo determinado, o incluso el cierre del centro de trabajo, cuando el Gobierno o los órganos de gobierno de las comunidades autónomas competentes en la materia entiendan que concurren circunstancias de excepcional gravedad en las infracciones, de conformidad con el art. 53 LPRL.

- El establecimiento de limitaciones a la facultad de contratar con la Administración por la comisión de delitos o infracciones administrativas muy graves en materia de seguridad y salud en el trabajo, conforme al art. 54 LPRL.

Para especificar la cuantía por la que se imponen las sanciones (en su grado mínimo, medio o máximo), dentro de las faltas leves, graves o muy graves, el art. 39.3 de LISOS establece un criterio de graduación conforme a los siguientes parámetros:

- La peligrosidad de las actividades desarrolladas en la empresa o centro de trabajo.

- El carácter permanente o transitorio de los riesgos inherentes a dichas actividades.

- La gravedad de los daños producidos o que hubieran podido producirse por la ausencia o deficiencia de las medidas preventivas necesarias.

- El número de trabajadores afectados.

- Las medidas de protección individual o colectiva adoptadas por el empresario y las instrucciones impartidas por éste en orden a la prevención de los riesgos.

- El incumplimiento de las advertencias o requerimientos previos a que se refiere el artículo 43 de la LPRL 6 .

- La inobservancia de las propuestas realizadas por los servicios de prevención, los delegados de prevención o el comité de seguridad y salud de la empresa para la corrección de las deficiencias legales existentes.

- La conducta general seguida por el empresario en orden a la estricta observancia de las normas en materia de prevención de riesgos laborales.

Los principios de la potestad sancionadora por parte de la Administración frente al empresario vienen recogidos en la Ley 39/2015, de 1 de octubre, del

\footnotetext{
${ }^{6}$ Letra f) del número 3 del artículo 39 redactada por el artículo decimotercero de la Ley 54/2003, de 12 de diciembre, de reforma del marco normativo de la prevención de riesgos laborales («B.O.E.» 13 diciembre y con vigencia desde el 14 de diciembre de 2003).
} 
procedimiento administrativo común de las administraciones públicas (en adelante, "Ley 39/2015") en sus arts. 134 a 138, inclusive ${ }^{7}$

Los principios relacionados con la potestad sancionadora administrativa son esencialmente los siguientes:

- Principio de legalidad: las infracciones y sanciones impuestas en el orden social deben recogerse en una norma con rango de ley.

- El principio de "presunción de inocencia". El art. 24.2 CE reconoce expresamente la presunción la inocencia, que significa que todos los ciudadanos tienen el derecho fundamental a ser considerados no autores o partícipes de infracciones penales, mientras que no se demuestre su culpabilidad. El derecho a la presunción de inocencia es plenamente extensivo al Derecho administrativo sancionador.

- Principio de irretroactividad: se aplican las disposiciones sancionadoras vigentes en el momento en que se produce el hecho constitutivo de infracción.

- Principio de tipicidad: las conductas que puedan constituir infracción deben venir definidas de forma clara y precisa en la ley, siendo estas clasificadas según su gravedad.

- Principio de proporcionalidad: entre la infracción cometida y la sanción a imponer debe existir un criterio proporcional y ajustado.

- El principio "non bis in ídem" que se recoge en el 3.1 de la LISOS: "No podrán sancionarse los hechos que hayan sido sancionados penal o administrativamente, en los casos en que se aprecie identidad de sujeto, de hecho y de fundamento".

\section{Procedimiento sancionador}

El procedimiento sancionador, común a todas las Administraciones públicas, se ajustará a lo previsto en la presente Ley y en la disposición adicional cuarta de la Ley 42/1997, de 14 de noviembre, Ordenadora de la Inspección de Trabajo y Seguridad Social, siendo de aplicación subsidiaria las disposiciones sobre procedimiento sancionador regulado en la Ley 39/2015, de 1 de

${ }^{7}$ Si bien la Ley 39/2015, recoge los principios que rigen el procedimiento sancionador de la Administración, en su Disposición Adicional $1^{\text {a }}$ de la Ley 39/2015 podemos observar como esta norma es de aplicación subsidiaria a los procedimientos administrativos que surjan en el ámbito social: "Los procedimientos administrativos para la imposición de sanciones por infracciones en el orden social y para la extensión de actas de liquidación de cuotas de la Seguridad Social se regirán por su normativa específica y, subsidiariamente, por las disposiciones de esta Ley”. 
octubre, del Procedimiento Administrativo Común de las Administraciones Públicas.

Las infracciones serán sancionadas en el ámbito de competencia de la Administración General del Estado, a propuesta de la Inspección de Trabajo y Seguridad Social (en adelante, "ITSS"), por los órganos a los que normativamente se haya atribuido la potestad sancionadora (art. 4 del RD 928/1998). El sujeto sancionador es, por tanto, la ITSS, que actuará por denuncia de los trabajadores o de oficio.

En cuanto al procedimiento sancionador hay que destacar que es preceptivo el requerimiento previo del Inspector de Trabajo con el objetivo de subsanar el incumplimiento empresarial:

- La Inspección de Trabajo y Seguridad Social levantará acta de infracción ${ }^{8}$ en la que practicará una "propuesta de sanción".

- La empresa declarada responsable de las infracciones que allí se indicaren, puede presentar alegaciones por plazo de 15 días.

- Si las alegaciones son desestimadas por el órgano competente de resolverlas, la empresa podrá interponer recurso de alzada en el plazo de 1 mes.

- Si el recurso de alzada es, a su vez, desestimado (por resolución expresa o por silencio administrativo), se iniciará el plazo para que la Empresa interponga demanda ante la jurisdicción social.

- Conforme al art. 72 LRJS: "En el proceso no podrán introducir las partes variaciones sustanciales de tiempo, cantidades o conceptos respecto de los que fueran objeto del procedimiento administrativo y de las actuaciones de los interesados o de la Administración”.

Tras la entrada en vigor de la Ley 36/2011, de 10 de octubre, Reguladora de la Jurisdicción Social (en adelante, "LRJS"), la jurisdicción social es la competente

${ }^{8}$ Según el art. 53 de la LISOS las actas de infracción de la Inspección de Trabajo y Seguridad Social, reflejarán: a) Los hechos constatados por el Inspector de Trabajo y Seguridad Social o Subinspector de Empleo y Seguridad Social actuante, que motivaron el acta, destacando los relevantes a efectos de la determinación y tipificación de la infracción y de la graduación de la sanción; b) La infracción que se impute, con expresión del precepto vulnerado; c) La calificación de la infracción, en su caso la graduación de la sanción, la propuesta de sanción y su cuantificación; d) En los supuestos en que exista posible responsable solidario, se hará constar tal circunstancia, la fundamentación jurídica de dicha responsabilidad y los mismos datos exigidos para el responsable principal. 
para conocer de las impugnaciones de las resoluciones administrativas recaídas en materia laboral, en detrimento de la jurisdicción contencioso- administrativa. La impugnación de resoluciones ante la jurisdicción social viene regulada en los artículos 72 y 80.1 c) LRJS.

\subsection{Responsabilidad de Seguridad Social. Recargo de prestaciones económicas} en caso de accidente de trabajo y enfermedad profesional

El Real Decreto Legislativo 8/2015, de 30 de octubre, por el que se aprueba el texto refundido de la Ley General de la Seguridad Social establece en el art. 164 la regulación por recargo de las prestaciones económicas derivadas de accidente de trabajo o enfermedad profesional de la siguiente forma:

1. Todas las prestaciones económicas que tengan su causa en accidente de trabajo o enfermedad profesional se aumentarán, según la gravedad de la falta, de un 30 a un 50 por ciento, cuando la lesión se produzca por equipos de trabajo o en instalaciones, centros o lugares de trabajo que carezcan de los medios de protección reglamentarios, los tengan inutilizados o en malas condiciones, o cuando no se hayan observado las medidas generales o particulares de seguridad y salud en el trabajo, o las de adecuación personal a cada trabajo, habida cuenta de sus características y de la edad, sexo y demás condiciones del trabajador.

2. La responsabilidad del pago del recargo establecido en el apartado anterior recaerá directamente sobre el empresario infractor y no podrá ser objeto de seguro alguno, siendo nulo de pleno derecho cualquier pacto o contrato que se realice para cubrirla, compensarla o trasmitirla.

3. La responsabilidad que regula este artículo es independiente y compatible con las de todo orden, incluso penal, que puedan derivarse de la infracción.

El recargo es una institución híbrida entre lo público y lo privado, por eso es catalogado en ocasiones como una sanción, pues su imposición se inicia por el inspector de trabajo, y en otras ocasiones como una indemnización pues el dinero lo percibe el trabajador compensando los daños ocasionados por el incumplimiento empresarial.

\subsection{Responsabilidad penal}

La responsabilidad penal del empresario motivada por el incumplimiento de sus obligaciones en materia de prevención, seguridad y salud en el trabajo 
viene regulada en el Código Penal. Esta responsabilidad penal es compatible con la responsabilidad civil y de seguridad social, pero incompatible con la responsabilidad administrativa cuando se produzca identidad de sujeto, hecho y fundamento.

En este ámbito podemos distinguir dos grupos de delitos:

- Los contenidos en los art. 316 a 318 del Código Penal que castigan la mera puesta en peligro de la vida, salud o integridad física de los trabajadores.

- Los delitos de resultado que imponen diferentes penas en función del resultado que se haya generado.

Nos vamos a referir primeramente al tipo específico dentro de los delitos contra los derechos de los trabajadores. Se trata de un "delito de peligro" como "delito contra la seguridad de los trabajadores" en los artículos 316 a 318 del Código Penal, aprobado por Ley Orgánica 10/1995, de 23 de noviembre.

Impone pena a aquellos que "con infracción de las normas de prevención de riesgos laborales y estando legalmente obligados, no faciliten los medios necesarios para que los trabajadores desempeñen su actividad con las medidas de seguridad e higiene adecuadas, de forma que pongan así en peligro grave su vida, salud o integridad física" La pena es de prisión de seis meses a tres años y multa de seis a doce meses.

El art. 317 se refiere a la imprudencia grave ${ }^{9} . Y$ en el art. 318 se refiere a los casos en que los hechos se atribuyan a personas jurídicas indicando que se impondrá la pena señalada a los administradores o encargados del servicio que hayan sido responsables de los mismos y a quienes, conociéndolos y pudiendo remediarlo, no hubieran adoptado medidas para ello ${ }^{10}$. En estos supuestos la autoridad judicial podrá decretar, además, alguna o algunas de las medidas previstas en el art. 129 de este Código ${ }^{11}$.

\footnotetext{
${ }^{9}$ En este caso la pena es la inferior en grado.

${ }^{10}$ Redactado por el número doce del artículo primero de la L.O. 11/2003, de 29 de septiembre, de medidas concretas en materia de seguridad ciudadana, violencia doméstica e integración social de los extranjeros («B.O.E.» 30 septiembre) con vigencia 1 de octubre de 2003.

${ }^{11}$ Estas penas son las siguientes: disolución de la sociedad, asociación o fundación, clausura de la empresa, sus locales o establecimientos, con carácter temporal o definitivo, clausura temporal no podrá exceder de 5 años, suspensión de las actividades de la sociedad, empresa, fundación o asociación por un plazo que no podrá exceder de 5 años, prohibición de realizar en el futuro actividades e intervención de la empresa para salvaguardar los derechos de los trabajadores o de los acreedores.
} 
El bien jurídico protegido de estos delitos es la seguridad en el trabajo por lo que no se exige que se haya producido ningún daño o resultado lesivo sino que es suficiente con que se haya puesto en peligro la vida, salud o integridad física de los trabajadores.

La pena correspondiente es de prisión de seis meses a tres años y multa de seis a doce meses, aplicable en grado inferior si fuera por imprudencia grave.

Los presupuestos del tipo penal son:

- No facilitar los medios necesarios para que los trabajadores desempeñen su actividad con la seguridad e higiene adecuadas.

- Que como consecuencia de lo anterior se ponga en peligro de forma concreta y grave para la vida, salud o integridad física de los trabajadores.

- Que se produzca infracción de las normas de prevención de riesgos laborales. Debe entenderse normativa en sentido amplio, desde la Ley de Prevención de Riesgos Laborales a la regulación específica de determinados agentes (cancerígenos, biológicos, amianto, ruido, etc.), lugares de trabajo (obras de construcción, buques, etc.), operaciones (manipulación de cargas), equipos de trabajo, etc. La infracción consiste en "no facilitar los medios necesarios para que los trabajadores desempeñen su actividad con las medidas de seguridad e higiene adecuadas". Este es el elemento más polémico con el que nos encontramos pues la norma penal realiza remisión a las normas en materia de prevención de riesgos laborales y hay una gran cantidad de regulación en este sentido. Por eso la jurisprudencia considera que nos hallamos ante una norma penal en blanco que se remite a normas muy diversas y que no sólo regula la prevención de riesgos laborarles sino a la normativa laboral cualquiera que sea su rango jerárquico.

En los casos en que los hechos sean atribuibles a persona jurídica, se impondrá la pena señalada a los administradores o encargados del servicio que hayan sido responsables de los mismos y a quienes, conociéndolos y pudiendo remediarlo, no hubieren adoptado medidas para ello (art. $318 \mathrm{CP}$ ).

Sobre la sociedad puede recaer la responsabilidad solidaria sobre la pena de multa y las medidas accesorias que se puedan adoptar. Los mandos intermedios, encargados, capataces, jefes de obra e, incluso, los técnicos y coordinadores de seguridad, pueden ser sujetos responsables y condenados, por el ejercicio de sus funciones en relación con los hechos ocurridos, es decir, todo aquel que tenga obligaciones concretas en materia de seguridad y salud laboral. 
En relación con las posibles conductas punibles relacionadas con la legislación reguladora de prevención de riesgos laborales podemos encontrar también, y en concurrencia con los anteriores, algunos tipos genéricos que consideran el resultado lesivo o de muerte que se ha producido con el incumplimiento: delito de homicidio, delito de lesiones y faltas contra las personas. Se trata de "delitos imprudentes y de resultado" aplicables a la seguridad y salud laboral, son tipos penales que no tienen un contenido preventivo específico, y que sancionan al autor en función del resultado provocado culposa o imprudentemente.

- Delito de homicidio imprudente (art. 138 y 142 del CP). La pena prevista es de prisión de uno a cuatro años. Si concurriera imprudencia profesional se impondrá la pena accesoria de la inhabilitación para el ejercicio de la profesión de tres a seis años.

- Delito de lesiones (art. 147 a 152 del CP). Producido mediante imprudencia grave, la pena va de prisión de tres meses a tres años, siempre que la lesión requiera objetivamente para su sanidad, además de una primera asistencia facultativa, tratamiento médico o quirúrgico.

- Delito de aborto imprudente (art. $146 \mathrm{CP}$ ). El que por imprudencia grave ocasionare un aborto será castigado con la pena de prisión de tres a cinco meses o multa de seis a 10 meses. ${ }^{12}$ Cuando el aborto fuere cometido por imprudencia profesional se impondrá asimismo la pena de inhabilitación especial para el ejercicio de la profesión, oficio o cargo por un período de uno a tres años. La embarazada no será penada a tenor de este precepto.

- Delito de lesiones al feto (art. 157 y $158 \mathrm{CP}$ ). El que, por cualquier medio o procedimiento, causare en un feto una lesión o enfermedad que perjudique gravemente su normal desarrollo, o provoque en el mismo una grave tara física o psíquica, será castigado con pena de prisión de uno a cuatro años e inhabilitación especial para ejercer cualquier profesión sanitaria, o para prestar servicios de toda índole en clínicas, establecimientos o consultorios ginecológicos, públicos o privados, por tiempo de dos a ocho años. El que, por imprudencia grave, cometiere los hechos descritos en el artículo anterior, será castigado con la pena de prisión de tres a cinco meses o multa de seis a 10 meses. ${ }^{13}$ Cuando los hechos descritos en el artículo anterior fueren cometidos por imprudencia profesional se impondrá asimismo la

12 Párrafo $10^{\circ}$ del artículo 146 redactado por el apartado quincuagésimo primero del artículo único de la L.O. 15/2003, de 25 de noviembre, por la que se modifica la L.O. 10/1995, de 23 de noviembre, del Código Penal («B.O.E.» 26 noviembre) con vigencia de 1 de octubre de 2004.

${ }^{13}$ Párrafo $1 .^{\circ}$ del artículo 158 redactado por el apartado quincuagésimo quinto del artículo único de la L.O. 15/2003, de 25 de noviembre, por la que se modifica la L.O. 10/1995, de 23 de noviembre, del Código Penal («B.O.E.» 26 noviembre) con vigencia 1 de octubre de 2004. 
pena de inhabilitación especial para el ejercicio de la profesión, oficio o cargo por un período de seis meses a dos años. La embarazada no será penada a tenor de este precepto.

- Delito de acoso laboral ${ }^{14}$ (art. 173.1 CP) que castiga al que ocasione un trato degradante, menoscabando gravemente su integridad moral que será castigado con la pena de prisión de seis meses a dos años. Con la misma pena serán castigados los que, en el ámbito de cualquier relación laboral o funcionarial y prevaliéndose de su relación de superioridad, realicen contra otro de forma reiterada actos hostiles o humillantes que, sin llegar a constituir trato degradante, supongan grave acoso contra la víctima.

- Delito de denegación de auxilio (art. $195 \mathrm{CP}$ ) que castiga a la persona que no socorre a otra que se encuentra desamparada y en peligro manifiesto y grave si pudiera hacerlo sin riesgo propio ni de terceros (Con multa de tres a doce meses).

En estos casos la relación de personas potencialmente susceptibles de ser responsables por los delitos de resultado es mucho más amplio dado que, junto con los legalmente obligados a facilitar los medios necesarios, se encuentran también las personas cuya posición de garante no deriva únicamente de la ley de prevención de riesgos laborales, sino también de otras fuentes de acuerdo a lo previsto en el art. 11 del CP.

Hay que destacar que tal y como se deduce del art. 77 del Código Penal y como viene interpretando la jurisprudencia "cuando como consecuencia de la infracción de normas de prevención de riesgos laborales se produzca el resultado que se pretendía evitar con ellos (muerte, lesiones, etc.) el delito de resultado absorberá al de peligro como una manifestación lógica de la progresión delictiva ${ }^{15}$.

\section{Cuestiones procedimentales}

La vía penal puede iniciarse de diversas formas:

${ }^{14}$ La reforma del Código Penal de la Ley Orgánica 5/2010 introduce este nuevo delito en los siguientes términos: "Serán castigados los que, en el ámbito de cualquier relación laboral o funcionarial y prevaliéndose de su relación de superioridad, realicen contra otro de forma reiterada actos hostiles o humillantes que, sin llegar a constituir trato degradante, supongan grave acoso contra la víctima". Como se aprecia, configura como delito el acoso vertical descendente (de superior a subordinado), no así el vertical ascendente (de subordinado a superior) o el horizontal (entre compañeros) que quedaría en la esfera de la responsabilidad civil, administrativa, laboral o de Seguridad Social. La pena asociada a este delito será de 6 meses a 2 años de prisión.

${ }^{15}$ STS de 14 de julio de 1999 recurso 3738/1999. 
I. Mediante denuncia o querella de los perjudicados

II. Mediante comunicación de la ITSS a la Fiscalía

III.Mediante actuación de oficio por parte de la Fiscalía o del Juzgado.

Hay que destacar como algunos de estos delitos exigen la presentación de denuncia por el agraviado para poder ser perseguidos, convirtiéndose en delitos semipúblicos. Una vez iniciado el procedimiento penal, en éste se dan dos fases importantes que se tramitan por separado y que se atribuyen a órganos jurisdiccionales diferentes:

- La fase de instrucción se tramita ante el juez de instrucción. Abrirá diligencias previas y se investigarán los hechos que puedan ser constitutivos de delito y la persona supuestamente responsable. Esta fase finalizará con una resolución denominada auto en el que juez decretará:

- El sobreseimiento total o parcial: Archivo de la causa por entender que los hechos no son constitutivos de delito o archivo de la causa con respecto a alguno de los sujetos que pudieran haber sido inicialmente imputados.

- La continuación del procedimiento.

- Fase de juicio oral en la que el juez instructor, si considera que los hechos puedan ser constitutivos de delito, eleva las actuaciones al órgano encargado de continuar con el procedimiento que será el Juzgado de lo Penal si la pena no supera los 5 años de privación de libertad o la Audiencia Provincial respectiva si la pena supera los 5 años. Es órgano será el encargado de celebrar juicio oral y de dictar la sentencia.

\subsection{Responsabilidad civil}

La responsabilidad civil del empresario ante el incumplimiento de sus obligaciones en materia de prevención de riesgos, seguridad y salud en el trabajo, se encuentra regulada en el Código Civil y en caso de que se ocasione daños tiene una triple vertiente ${ }^{16}$ que debe ser considerada por separado:

${ }^{16}$ La Sala de lo Social del Tribunal Supremo (por todas, en su Sentencia de 30 de junio de 2010) ha delimitado ambas responsabilidades considerando: responsabilidad contractual aquella basada en un incumplimiento de las obligaciones impuestas al empresario por las normas legales o convencionales en materia de prevención de riesgos laborales; y responsabilidad extracontractual, la generada cuando la obligación de evitar el daño excede de la estricta órbita del contrato de trabajo, hasta el punto de que los perjuicios causados hubieran sido igualmente indemnizables sin la existencia del mismo. 
- Contractual (art. 1101 a 1107 del Código Civil) en relación con la responsabilidad entre la empresa incumplidora y el trabajador accidentado al existir un incumplimiento del deber de protección del trabajador en el marco del contrato de trabajo, aunque también podrá canalizarse por la vía de la responsabilidad extracontractual.

- Extracontractual (art. 1902 a 1904 Código Civil) en relación con la responsabilidad civil entre la empresa incumplidora y un tercero accidentado al no existir nexo contractual alguno entre los implicados.

- La derivada del ejercicio de la acción civil en relación con la responsabilidad penal.

El plazo de prescripción es de un año a contar desde el día en que la acción pudiera ejercitarse (art. 59.2 del Estatuto de los Trabajadores y art. 1968 del Código Civil). Hay que destacar que en casos de responsabilidad civil el empresario no responde de los casos fortuitos ni de los supuestos de fuerza mayor, si bien la empresa debe prever las distracciones o imprudencias no temerarias del trabajador tal y como establece el art. 15.4 de la LPRL.

Los posibles responsables contra los que se pueden interponer las acciones de reclamación por responsabilidad civil son muy amplios. A ello, debemos añadir que los perjudicados suelen demandar por exceso, ante una pluralidad de posibles responsables para aumentar sus posibilidades de éxito.

- El empresario responderá civilmente por actos de sus empleados, entendiendo como tal cualquier miembro de la estructura organizativa, en cumplimiento de las instrucciones de la empresa. El caso más típico será la responsabilidad empresarial frente a las lesiones padecidas por uno de sus empleados, cuando se demuestre que existían deficiencias preventivas que influyeron en el daño padecido por el trabajador.

- Los servicios de prevención de riesgos laborales cuando la actuación negligente de sus técnicos o sanitarios guarde una relación causal con el accidente.

- Los fabricantes, importadores o suministradores de maquinaria, equipos, productos y útiles de trabajo.

- Las auditorías de prevención de riesgos laborales en su actividad negligente como entidades auditoras.

- En el ámbito de obras de construcción: promotores, técnicos competentes, coordinadores de seguridad y salud en el trabajo, etc. 
- El trabajador autónomo contratado que causa un daño por un riesgo de su actividad del cual no informó al empresario contratante.

- Las respectivas aseguradoras por contratación de seguro de responsabilidad civil. La responsabilidad civil, derivada o no de delito es asegurable de conformidad con lo establecido en el art. 15.5 de la LPRL y el art. 117 del CP.

En este sentido, "los aseguradores que hubieren asumido el riesgo de las responsabilidades pecuniarias derivadas del uso o explotación de cualquier bien, empresa, industria o actividad, cuando, como consecuencia de un hecho previsto en este Código [penal], se produzca el evento que determine el riesgo asegurado, serán responsables civiles directos hasta el límite de la indemnización legalmente establecida o convencionalmente pactada, sin perjuicio del derecho de repetición contra quien corresponda".

Por eso conviene que los empresarios suscriban la respectiva póliza de responsabilidad civil que cubra las posibles indemnizaciones por daños y perjuicios. Debe prestarse especial atención al tope de cobertura de la póliza, por cuanto algunas de ellas establecen una prima baja, pero tienen un límite por siniestro o anual, que puede sobrepasarse en función de la gravedad de las secuelas de un accidente. También pueden establecerse mayores o menores franquicias que afectan a las cuantías de las primas y posteriormente a las coberturas en caso de siniestro.

Asimismo, deberá vigilarse que el ámbito de cobertura no se circunscriba a los empleados propios, por cuanto siempre existe el riesgo de causar daños a trabajadores de empresas subcontratadas (especialmente en obras de construcción), trabajadores autónomos o incluso terceros que acudan a instalaciones.

Téngase en cuenta que la indemnización por fallecimiento o enfermedad grave puede estar entre 100.000 y 300.000 euros en función de las circunstancias familiares del perjudicado, y que en casos muy dramáticos, como paraplejias o tetraplejias, pueden alcanzarse indemnizaciones entre 1 y 2 millones de euros. Los Servicios de Prevención Ajenos vienen obligados por la normativa vigente a tener suscrita una póliza que cubra la actuación de sus técnicos y sanitarios.

\section{A) Responsabilidad civil contractual}

Cuando el empresario incumpla sus obligaciones en materia de prevención de riesgos laborales dentro del ámbito de la relación laboral, será responsable de 
conformidad con la regla general que establece el art. 1101 del Código Civil: "quedan sujetos a la indemnización de los daños y perjuicios causados los que en el cumplimiento de sus obligaciones incurrieren en dolo, negligencia o morosidad, y los que de cualquier modo contravinieren al tenor de aquéllas".

Los requisitos que deben concurrir para la existencia de responsabilidad civil pueden resumirse en los siguientes:

1. Existencia de daño al trabajador por acción u omisión, consistente en un incumplimiento, normalmente grave, por parte del empresario de sus obligaciones en materia de seguridad y salud en el trabajo.

a. El art. 4.3 de la Ley de Prevención de Riesgos Laborales especifica que "se considerarán como daños derivados del trabajo las enfermedades, patologías o lesiones sufridas con motivo u ocasión del trabajo". Hay que aclarar que el concepto de daño debe entenderse en un sentido muy amplio, como cualquier perjuicio físico, moral o económico, incluyendo el daño emergente o el lucro cesante.

b. El perjudicado deberá acreditar los daños sufridos: secuelas físicas, días de incapacidad temporal, pérdidas materiales, sanción administrativa, interrupción de la producción, etc.

c. El daño debe ser cuantificable económicamente bien por acuerdo de las partes o por decisión judicial. Para determinar la indemnización se seguirán los criterios de la Ley 36/2011 que establece unas tablas indemnizatorias, si bien en ausencia de las mismas, suelen utilizarse los baremos aplicables a accidentes de tráfico.

2. Falta de la debida diligencia del empresario

a. La diligencia debida ha sido definida por la jurisprudencia como "la perseverancia exigible y la reflexión necesaria, con vistas a evitar el perjuicio en los bienes ajenos jurídicamente protegidos". (STS Civil de 2-11-1988).

b. Si nos hallamos ante profesionales especializados, su "mala praxis" podrá dar lugar a la indemnización: por ejemplo, técnicos de prevención que no contemplen un riesgo, sanitarios que no califiquen debidamente la aptitud laboral, coordinadores de seguridad y salud que elaboren un estudio improcedente, higienistas que efectúen unas mediciones erróneas. 
3. Relación de causalidad entre la conducta empresarial y el daño producido.

a. Debe existir relación de causalidad entre el comportamiento (por acción u omisión) del sujeto causante y el daño infringido al trabajador.

b. La responsabilidad puede ser ponderada si concurriera culpa del sujeto perjudicado en el acaecimiento de los hechos.

Para reclamar este tipo de responsabilidades, antes de interponer la demanda por daños y perjuicios, se suele intentar la reclamación extrajudicial en la que el sujeto perjudicado solicita al supuesto causante una compensación económica. En el caso de que no lleguen a un acuerdo por vía de negociación, mediación o conciliación la reclamación terminará en demanda ante los tribunales de justicia.

Conforme al art. 2.b de la Ley 36/2011 de 10 de octubre reguladora de la jurisdicción social que entró en vigor el 11 de diciembre de 2011 la demanda debe interponerse ante los juzgados de lo social por referirse al ámbito de la prestación de servicios incluida la acción directa contra la aseguradora.

La práctica más habitual es que el perjudicado se dirija frente a todos los sujetos posible (empresario, contratista, subcontratista, fabricante en su caso, servicio de prevención de riesgos laborales, etc.) aumentando así las posibilidades de conseguir la satisfacción de sus pretensiones.

Esta responsabilidad consistirá, básicamente, en satisfacer una indemnización de daños y perjuicios al perjudicado que será fijada por el tribunal correspondiente con carácter discrecional (art. $1.103 \mathrm{CC}$ ) en atención a las circunstancias concurrentes y a los daños realmente producidos. Como señala acertadamente la STS 2-10-2000, "el trabajador accidentado o sus causahabientes tienen, como regla, derecho a su reparación íntegra, así como que las consecuencias dañosas de los accidentes de trabajo no afectan solo al ámbito laboral y a la merma de capacidad de tal naturaleza que pueda sufrir el trabajador accidentado, sino que pueden repercutir perjudicialmente en múltiples aspectos o facetas de su vida personal, familiar o social de aquél y de las que personas que del mismo dependan".

\section{B) Responsabilidad civil extracontractual}

Se produce cuanto por acción u omisión se causa daño a otro interviniendo culpa o negligencia conforme a la previsión general del art. 1902 del CC. 
Para apreciar la responsabilidad civil extracontractual debe cumplirse un triple requisito que resulta aplicable en todos los casos:

- Que exista una norma jurídica que imponga un deber diligente de actuación al empresario y se haya producido una conducta que incumpla esa diligencia debida.

- Que haya un perjuicio para un tercero (con independencia de si existe o no relación negocial entre ambas).

- Que exista relación de causalidad entre la conducta del sujeto y la producción del daño.

Para reclamar este tipo de responsabilidades antes de interponer demanda por daños y perjuicios se suele intentar la reclamación extrajudicial en la que el sujeto perjudicado solicita al supuesto causante una compensación económica. Si no se alcanza un acuerdo por vía de negociación, mediación o conciliación la reclamación terminará en demanda ante los tribunales de justicia. En caso de responsabilidad civil extracontractual la jurisdicción competente será la jurisdicción civil. Y el procedimiento será el procedimiento verbal o el procedimiento ordinario en función de la cuantía de la indemnización que se reclame según que sea menor o mayor de 6.000 euros.

\section{C) Responsabilidad civil en relación con la responsabilidad penal}

El Código Penal regula esta materia en los arts. 110 y siguientes, según los cuales la ejecución de un hecho descrito por la Ley como delito obliga a reparar, en los términos previstos en las Leyes, los daños y perjuicios causados. La responsabilidad establecida comprenderá la restitución, la reparación del daño y la indemnización de perjuicios materiales y morales ${ }^{17}$.

El empresario puede quedar sujeto a una responsabilidad civil por la comisión de un delito si de sus actos $\mathrm{u}$ omisiones se derivan perjuicios de cualquier género. Así lo establece el art. $116 \mathrm{CP}$ según el siguiente tenor ${ }^{18}$ :

${ }^{17} \mathrm{Si}$ se aprecia la existencia de delito la acción penal puede sustanciarse conjuntamente con la civil según establecen nuestras normas de derecho sustantivo y de derecho procesal en el ámbito penal de manera que el responsable del delito podrá ser condenado a la restitución de la cosa, la reparación del daño y la indemnización de los perjuicios.

${ }^{18}$ El número 1 del artículo 116 redactado por el número cincuenta y siete del artículo único de la L.O. 1/2015, de 30 de marzo, por la que se modifica la L.O. 10/1995, de 23 de noviembre, del Código Penal («B.O.E.» 31 marzo) y ha entrado en vigor el 1 de julio de 2015. El número 3 del artículo 116 introducido por el apartado vigésimo noveno del artículo único de la 
1. Toda persona criminalmente responsable de un delito lo es también civilmente si del hecho se derivaren daños o perjuicios. Si son dos o más los responsables de un delito los jueces o tribunales señalarán la cuota de que deba responder cada uno.

2. Los autores y los cómplices, cada uno dentro de su respectiva clase, serán responsables solidariamente entre sí por sus cuotas, y subsidiariamente por las correspondientes a los demás responsables. La responsabilidad subsidiaria se hará efectiva: primero, en los bienes de los autores, y después, en los de los cómplices. Tanto en los casos en que se haga efectiva la responsabilidad solidaria como la subsidiaria, quedará a salvo la repetición del que hubiere pagado contra los demás por las cuotas correspondientes a cada uno.

3. La responsabilidad penal de una persona jurídica llevará consigo su responsabilidad civil en los términos establecidos en el artículo 110 de este Código de forma solidaria con las personas físicas que fueren condenadas por los mismos hechos.

Dicha responsabilidad civil se regula por lo establecido en el Código Penal, por expresa remisión del art. 1.902 del Código Civil: "las obligaciones que nazcan de los delitos o faltas se regirán por las disposiciones del Código Penal".

\subsection{Compatibilidad de los diferentes tipos de responsabilidad}

- La responsabilidad penal es incompatible con la responsabilidad administrativa, cuando haya identidad de sujeto, de hechos y fundamentos de derecho ya que ambas son responsabilidades públicas y se anulan entre sí de manera que se impone la una o la otra pero nunca las dos simultáneamente. Se aplica el principio "Non bis in idem", conforme al art. 3.1 del Real Decreto Legislativo 5/2000, de 4 de agosto, por el que se aprueba el Texto Refundido de la Ley sobre Infracciones y Sanciones en el Orden Social (en adelante, "LISOS"): "No podrán sancionarse los hechos que hayan sido sancionados penal o administrativamente, en los casos en que se aprecie identidad de sujeto, de hecho y de fundamento."

- La responsabilidad penal es compatible con la responsabilidad civil por los daños y perjuicios que pudieren derivarse del incumplimiento de obligaciones en materia de prevención de riesgos laborales.

L.O. 5/2010, de 22 de junio, por la que se modifica la L.O. 10/1995, de 23 de noviembre, del Código Penal («B.O.E.» 23 junio) y ha entrado en vigor el día 23 de diciembre de 2010. 
- La responsabilidad penal también es compatible con las responsabilidades en materia de recargo de prestaciones de la Seguridad Social.

- La responsabilidad civil es compatible con todas las responsabilidades, de cualquier orden penal o administrativo, que pudieran darse con motivo del incumplimiento empresarial en materia de seguridad, higiene y salud en el trabajo o en materia de prevención de riesgos.

- La responsabilidad por recargo de prestaciones es compatible con la responsabilidad administrativa, penal y civil.

Por tanto por un mismo hecho son perfectamente compatibles las responsabilidades administrativas o penales con responsabilidades civiles y responsabilidades por recargo de prestaciones sociales.

Jurisdicción competente en reclamaciones por responsabilidad civil y responsabilidad laboral: la doctrina contenida en la sentencia del Tribunal Supremo del "Caso Uralita".

El grupo uralita fue un grupo industrial importante: en el siglo XX producía un material resistente e ignifugo, moldeable y duradero que se utilizaba en construcción masivamente para planchas, tubos de presión, depósitos de agua, etc.

Las fibras de amianto que forman la uralita se expanden por la aire y con muy nocivas por inhalación.

En 1976 se promueven los primeros informes sobre los peligros del amianto, y se proponen revisiones médicas para reclamar la prohibición del amianto.

En la década de los 80 se empieza a exigir la sustitución del amianto y la reconversión tecnológica con mejoras en investigación y reciclaje de empleados.

En 1999 una Directiva comunitaria prohíbe "la utilización, producción y comercialización de las fibras de amianto y los productos que lo contenga". En nuestro país la prohibición se hizo efectiva desde diciembre de 2001.

Desde entonces se han interpuesto decenas de reclamaciones exigiendo indemnización por virtud de responsabilidad civil:

- Demandas por responsabilidad civil contractual por trabajadores o por los familiares de los trabajadores fallecidos. 
- Demandas por responsabilidad civil extracontractual:

- Tanto por parte de familiares afectados también por la enfermedad

- Como por vecinos de los centros industriales que inhalaron el amianto y contrajeron enfermedades.

Históricamente en España se había suscitado un conflicto entre la jurisdicción civil y penal con motivo de la competencia para decidir sobre la responsabilidad del empresario por daños sufridos por sus trabajadores.

- La jurisprudencia de la Sala Civil del TS generalmente venía asumiendo su competencia pues consideraba al empleado un particular que reclamaba indemnización a su empresario, también particular por un hecho sucedido en España por virtud de responsabilidad extracontractual pues las pretensiones de reparación del daño no se basaban en derechos y obligaciones del contrato de trabajo, sino en otro tipo de responsabilidad fundamentando la competencia de la jurisdicción civil en el art. $22.3^{\circ}$ de la Ley Orgánica del Poder Judicial (en adelante LOPJ). Esta jurisprudencia fue cuestionada por la doctrina laboralista defendiendo la competencia exclusiva de la jurisdicción social que es más específica que la jurisdicción civil.

- Sin embargo en algunos otros casos ${ }^{19}$ el TS venía manteniendo que la responsabilidad por accidentes de trabajo y vulneraciones de las normas de prevención de riesgos laborales y seguridad e higiene en el trabajo se trataba de una reclamación inherente al propio contrato de trabajo y por tanto correspondía conocer al orden social según el art. 9.5 de la LOPJ.

- La Sala Especial de Conflictos de Competencia del TS, encargada de resolver este tipo de conflictos entre el orden civil y el orden penal también afirmaba regularmente la competencia del orden social en las demandas de responsabilidad civil por accidentes de trabajo ${ }^{20}$.

- La sentencia de 15 de enero de 2008 de la Sala Primera resolvió está cuestión debatida y estableció un criterio para determinar la competencia de la jurisdicción social en caso de incumplimiento de normas laborales de prevención de riesgos laborales. El caso era el siguiente:

- En 1995 falleció un trabajador de la construcción al caerle encima parte de la estructura metálica de una nave industrial por

\footnotetext{
${ }^{19}$ SSTS de 10 de febrero de 1998, 24 de octubre de 1998, 11 de febrero de 2000, 26 de mayo de 2000 o 4 de mayo de 2006.

${ }^{20}$ En este sentido pueden verse autos de 23 de diciembre de 1993, 4 de abril de 1994, 10 de junio de 1996, 21 de diciembre de 200023 de diciembre de 2001, etc.
} 
incumplimiento de las normas en materia de prevención y seguridad en el trabajo y se reclamaban unos quince millones de las antiguas pesetas a la empresa para la que trabajaba.

- El juzgado de primera instancia determina que se trata de un ilícito laboral y que debe examinarse en esta vía y no en la civil por lo que se declara incompetente para conocer de la reclamación.

- La parte demandante recurre a la Audiencia Provincial que anuló esa sentencia de primera instancia y condenó a pagar la indemnización pretendida.

- La STS de la sala de lo Civil de 15 de enero de 2018 puso fin al proceso y considera que el incumplimiento de las normas de prevención de riesgos laborales, seguridad e higiene en el trabajo, suponen un incumplimiento del contrato y que por tanto no era competente para conocer del asunto la jurisdicción civil. Fue una decisión muy relevante y resolvía un importante problema que venía existiendo hasta el momento.

- Carecía de sentido que el trabajador damnificado pudiera decidir sobre la jurisdicción competente para conocer de su reclamación de indemnización por responsabilidad civil contractual o extracontractual pues lo verdaderamente relevante era si el empresario cumplió o no las normas de prevención de riesgos laborales que eran aplicables.

- Posteriormente se ha dictado una sentencia que ha tenido una gran repercusión mediática por el gran número de personas afectadas, las cantidades indemnizatorias que se solicitan y porque termina de concretar el panorama en las reclamaciones de responsabilidad civil contra los empresarios españoles. El caso era el siguiente:

- En el año 2007 cuarenta y nueve afectados por la exposición al amianto presentan demanda de responsabilidad civil ante los juzgados de Madrid frente a la empresa Uralita en reclamación de unos tres millones y medio de euros. Todos eran víctimas del amianto, la mayor parte familiares de los trabajadores fallecidos por las fibras del amianto debido a enfermedades pulmonares y cáncer y además demandaban también tres amas de casa, esposas de los trabajadores de las empresas demandadas que tenían enfermedades provocadas por el amianto como consecuencia de la inhalación de sus fibras al manipular la ropa de trabajo de los maridos. 
- El juzgado de primera instancia confirma su propia competencia objetiva y declara la responsabilidad civil de la empresa demanda modificando a la baja las cuantías solicitadas por la parte actora.

- La Audiencia Provincial de Madrid también mantiene su competencia si bien modifica la cuantía de las indemnizaciones concedidas.

- El Tribunal Supremo en este caso tan importante y con tanta repercusión para el derecho español de daños y su arquitectura jurisdiccional da una solución inédita hasta la fecha y novedosa al dilema sobre su competencia y a los efectos que aquí nos interesa declara que:

- La enfermedad que causó el fallecimiento de los trabajadores tenía su causa en la relación laboral por afectar a la infracción de normas de prevención de riesgos laborales y normas de seguridad e higiene en el trabajo, por tanto la jurisdicción competente debe ser la social por lo que derivó el conocimiento de estas reclamaciones a un nuevo procedimiento social iniciado al efecto. Considera el TS que los trabajadores afectados y sus sucesores se van a ver mejor amparados en la jurisdicción específica que es la social.

- Mientras que las amas de casa que reclaman por su enfermedad originada por la manipulación de las ropas de sus maridos, trabajadores de Uralita, lo hacen en virtud de responsabilidad civil extracontractual y por tanto es competencia de la jurisdicción civil por lo que entra a resolver sobre las indemnizaciones que concede. En este caso su pretensión de indemnización era desligada de toda relación laboral con el demandado por tanto corresponde conocer a los órganos jurisdiccionales civiles por responsabilidad extracontractual.

- De esta forma este caso no tiene en consideración de asegurar la continencia de la causa y evitar que una misma causa pudiera ser objeto de análisis por jueces de dos jurisdicciones distintas que pudieran llegar a soluciones diferentes por eso determina la diversidad de jurisdicciones y procesos para conocer de ese tipo de responsabilidades civiles.

- Así pues el tema de la reclamación por responsabilidad civil contra empresarios españoles ha quedado aclarado: para enjuiciar las controversias entre empresario y trabajador en el ámbito de la responsabilidad civil 
por accidentes de los trabajadores es aplicable el art. 2.b de la Ley 36/2011 de 10 de octubre reguladora de la Jurisdicción Social que entró en vigor el 11 de diciembre de 2011 es el orden social puesto que el deber de protección a la salud está integrado en el contrato de trabajo. Sin embargo para reclamaciones por responsabilidad civil extracontractual corresponde a la jurisdicción civil.

Desde entonces y una vez aclarada la doctrina de nuestro Tribunal Supremo se han dictado sentencias en las que se condena por responsabilidad civil contractual derivada del contrato de trabajo o responsabilidad civil extracontractual no solo a favor de las amas de casa que manipulaban la ropa de sus maridos, trabajadores de uralita, para lavarla, sino también a favor de personas con domicilios cercanos a las fábricas de uralita y que inhalaron el polvo de amianto.

La competencia de la jurisdicción social o civil tiene tres importantes consecuencias procesales:

- La inversión de la carga de la prueba en relación con la diligencia del empresario. Esto refuerza la posición del trabajador y el carácter objetivo de la responsabilidad civil y genera que el empresario demandado deba probar su diligencia o la imprudencia temeraria del trabajador accidentado.

- Cálculo de la indemnización que deberá ser adecuada, proporcionada y suficiente para alcanzar a reparar o compensar plenamente todos los daños y perjuicios (daño emergente, lucro cesante, daños materiales y morales), que como derivados del accidente de trabajo se acrediten sufridos en las esferas personal, laboral, familiar y social. Deberá tenerse en cuenta para su determinación la eventual concurrencia de culpas entre el trabajador y empresario por incumplimiento mutuo de sus respectivas obligaciones en materia de prevención de riesgos laborales. Esta es la labor más difícil con la que se encuentra un juez en los procesos sobre responsabilidad civil por accidente de trabajo es cuantificar el importe de la indemnización. La STC 181/2000 de 29 de junio declara la constitucionalidad del baremo de valoración de daños y perjuicios por accidente de tráfico y que actualmente se encuentra regulado pero sin embargo la sala cuarta del TS considera que el baremo puede ayudar a los jueces de lo social a valorar pero que no es vinculante de manera que pueden razonar y justificar por qué no lo aplican.

- Descuento de prestaciones percibidas del sistema de protección de la seguridad social. Hasta ahora eran frecuentes las sentencias que declaraban compatibles las indemnizaciones civiles con las prestaciones percibidas 
sin realizar ningún tipo de descuento. Hoy en día, sin embargo, se ha fundamentado ya por la Sala Cuarta del TS que deben deducirse las prestaciones percibidas de la indemnización con cargo a responsabilidad civil en la necesidad de evitar el enriquecimiento injusto de un trabajador para que no cobre dos veces por lo mismo. Esta cuestión del descuento es ciertamente una operación compleja por lo que debe realizarse partida por partida.

\section{RESPONSABILIDAD DEL TRABAJADOR}

De conformidad con la normativa el art. 29 de la LPRL:

Corresponde a cada trabajador velar, según sus posibilidades y mediante el cumplimiento de las medidas de prevención que en cada caso sean adoptadas, por su propia seguridad y salud en el trabajo y por la de aquellas otras personas a las que pueda afectar su actividad profesional, a causa de sus actos y omisiones en el trabajo, de conformidad con su formación y las instrucciones del empresario.

En este sentido de acuerdo con la formación de los trabajadores y siguiendo las instrucciones del empresario, deberán en particular cumplir las siguientes obligaciones:

- $1 .^{\circ}$ Usar adecuadamente, de acuerdo con su naturaleza y los riesgos previsibles, las máquinas, aparatos, herramientas, sustancias peligrosas, equipos de transporte $\mathrm{y}$, en general, cualesquiera otros medios con los que desarrollen su actividad.

- 2. ${ }^{\circ}$ Utilizar correctamente los medios y equipos de protección facilitados por el empresario, de acuerdo con las instrucciones recibidas de éste.

- $3 .^{\circ}$ No poner fuera de funcionamiento y utilizar correctamente los dispositivos de seguridad existentes o que se instalen en los medios relacionados con su actividad o en los lugares de trabajo en los que ésta tenga lugar.

- 4. ${ }^{\circ}$ Informar acerca de cualquier situación que entrañe un riesgo para la seguridad y la salud de los trabajadores.

- 5. ${ }^{\circ}$ Contribuir al cumplimiento de las obligaciones establecidas por la autoridad competente con el fin de proteger la seguridad y la salud de los trabajadores en el trabajo. 
- $6 .^{\circ}$ Cooperar con el empresario para que éste pueda garantizar unas condiciones de trabajo que sean seguras y no entrañen riesgos para la seguridad y la salud de los trabajadores.

El incumplimiento de las obligaciones legales que se imponen a los trabajadores por la regulación de prevención de riesgos laborales tendrá la consideración de incumplimiento laboral a los efectos previstos en el artículo 58.1 del Estatuto de los Trabajadores o de falta, en su caso, conforme a lo establecido en la correspondiente normativa sobre régimen disciplinario de los funcionarios públicos o del personal estatutario al servicio de las Administraciones públicas. Lo dispuesto en este apartado será igualmente aplicable a los socios de las cooperativas cuya actividad consista en la prestación de su trabajo, con las precisiones que se establezcan en sus Reglamentos de Régimen Interno.

Además de este tipo de responsabilidades tenemos que destacar también las responsabilidades civiles en que pueden incurrir los trabajadores en la medida que cause daño a terceros pues vendrá obligado a responder por ello en virtud de la obligación genérica contenida en el Código Civil de no causar daño a nadie que impone el art. 1902 del Código Civil (responsabilidad civil extracontractual): "el que por acción u omisión causa daño a otro, interviniendo culpa o negligencia, está obligado a reparar el daño causado".

No obstante, debe recordarse que, aun existiendo responsabilidad del trabajador, por el juego del art. 1903 del Código Civil el empresario puede verse obligado a responder civilmente por los actos de sus trabajadores: " $\mathrm{La}$ obligación que impone el artículo anterior es exigible, no sólo por los actos u omisiones propios, sino por los de aquellas personas de quienes se debe responder. (...) Lo son igualmente los dueños o directores de un establecimiento y empresa respecto de los perjuicios causados por sus dependientes en el servicio de los ramos en que los tuvieran empleados, o con ocasión de sus funciones".

Esta responsabilidad civil es de carácter solidario de forma que el tercero perjudicado podrá dirigirse, indistintamente, contra el trabajador, contra el empresario o contra ambos simultáneamente (art. 1144 CC). En todo caso, el empresario, en el supuesto que el trabajador hubiera actuado sin seguir sus órdenes, podrá repetir contra el mismo en el caso que hubiese reparado el daño causado por éste (art. 1145 CC) $)^{21}$.

${ }^{21}$ El art. 120 Código Penal establece que cuando existe responsabilidad penal del trabajador, el empresario podría responder civilmente, si bien con carácter subsidiario por insolvencia del trabajador. 


\section{CONCLUSIÓN}

A pesar de las mejoras e inversiones realizadas en materia de prevención de riesgos laborales la siniestralidad sigue siendo alta y además es una de las grandes preocupaciones en el ámbito empresarial por los costes que supone. Nuestro ordenamiento jurídico dispone de un sistema potente y efectivo de responsabilidades ante el incumplimiento de las normas de prevención de riesgos laborales, tal y como establece el art. 42 de la LPRL.

En este sentido el contenido de este artículo resulta determinante y cumple una función disuasoria frente al incumplimiento de las normas que se establecen para proteger la salud de los trabajadores pues se integra un régimen completo y sólido de responsabilidad, con efectividad de 360 grados, con normas de derecho penal con sancionan con una pena los hechos, con normas de derecho civil que generan una compensación económica para reparar el daño y perjuicio ocasionado y que puede cobrar el trabajador afectado o sus familiares en caso de fallecimiento, y al mismo tiempo garantiza la inspección por parte de las autoridades administrativas correspondientes y además establece recargos en prestaciones sociales que paga la empresa y cobra el accidentado o sus familiares.

Desde nuestro punto de vista, y como en nuestro país existen altas tasas de siniestralidad laboral, es necesario que exista este cuádruple sistema de responsabilidades ante las infracciones con penas del Código Penal, sanciones administrativas, indemnizaciones civiles y cláusulas indemnizatorias por vía de recargo de las prestaciones de la seguridad social para que el sistema sea efectivo.

El coste de los incumplimientos para los empresarios supone cuantías elevadas si tenemos en consideración que pueden concurrir responsabilidades penales o administrativas junto con responsabilidades civiles y de recargo de prestaciones a la Seguridad Social, y además importantes costes añadidos en el mercado o la imagen y reputación de la empresa. El resultado es un exigente sistema que garantiza que se cumplan al máximo las normas de prevención de riesgos laborales.

La mayor crítica que había tenido este sistema es la deficiente articulación por concurrir los distintos órdenes jurisdiccionales con criterios también diferentes a la hora de establecer responsabilidades lo que generaba inseguridad jurídica y algunas contradicciones entre sentencias. Desde nuestro punto de vista la inseguridad jurídica existente antes de la STS de Uralita era mayor por lo que valoramos muy positivamente la clarificación que se efectúa con la sentencia sobre la jurisdicción competente. 
Quizá en el futuro podrían mejorarse algunos aspectos para crear mejores condiciones de cumplimiento de este sistema de responsabilidades en relación con la prevención de riesgos laborales para conseguir una mayor intervención de los inspectores de trabajo para controlar las infracciones administrativas, para conseguir la labor de los físcales para la persecución de este tipo de delitos, para incrementar la participación de los representantes de los trabajadores y los sindicatos en el control del cumplimiento de las obligaciones establecidas legalmente y exigir las correspondientes responsabilidades, y, en general, con una mayor rapidez judicial en la tramitación de este tipo de asuntos. 
